\title{
Effects of ageing on peroxidase activity and localization in radish (Raphanus sativus L.) seeds
}

\author{
A. Scialabba' ${ }^{1}$ L.M. Bellani ${ }^{2}$, and A. Dell'Aquila ${ }^{3}$
}

${ }^{1}$ Dipartimento di Scienze Botaniche, University of Palermo, 90123 Palermo, Italy; ${ }^{2}$ Dipartimento di Biologia Evolutiva, University of Siena, 53100 Siena, Italy and ${ }^{3}$ Istituto del Germoplasma, CNR, 70126, Bari, Italy

Accepted: 24/05/02

Key Words: Raphanus sativus, ageing, germination, peroxidase, cytochemistry

\section{SUMMARY}

Peroxidase activity was assayed in crude extracts of integument, cotyledons and embryo axis of radish seeds, deteriorated under accelerated ageing conditions. Over five days of ageing, in which germination decreased from 100 to $52 \%$, the enzyme activity in integument was higher than that in other seed parts, increasing in the first days of ageing and then decreasing sharply in extremely aged seeds. Polyacrylamide gel electrophoresis analysis showed four peroxidase isoenzymes with $\mathrm{MM}$ of $98,52.5,32.8$ and $29.5 \mathrm{kDa}$ in the embryo axis of unaged seeds, and only the 32.8 and $29.5 \mathrm{kDa}$ MM isoforms in the integument and cotyledons. In these parts of the seed, only the $29.5 \mathrm{kDa}$ MM isoenzyme increased in activity in early days of ageing and decreased thereafter. In the embryo axis, the $29.5 \mathrm{kDa} \mathrm{MM}$ isoenzyme activity increased slowly in the first day of ageing, while the 98 and $52.5 \mathrm{kDa} \mathrm{MM}$ isoenzyme activities disappeared. A cytochemical localization of peroxidase activity in the various tissues showed that main differences between unaged and extremely aged seeds occurred in the embryo axis.

\section{INTRODUCTION}

Peroxidases (EC.1.11.1.7, PODs) have been reported to have various physiological roles in plant tissues (Gille and Joenge, 1991), including oxidation of a wide range of biomolecules by accumulation of active forms of oxygen, such as the superoxide radical $\left(\mathrm{O}_{2}{ }^{--}\right)$, the hydroxyl radical $(\mathrm{OH})$, and hydrogen peroxide $\left(\mathrm{H}_{2} \mathrm{O}_{2}\right)$. The most frequently cited cause of seed deterioration is lipid peroxidation, which may begin with production of free radicals, leading to cell damage and seed death (Wilson and McDonald, 1986; McDonald, 1999). In soybean (Stewart and Bewley, 1980; Sung and Chiu, 1995), Acer platanoides (Pukacka, 1991), peanut (Sung and Jeng, 1994), watermelon (Chiu et al., 1995) and sunflower (Bailly et al., 1998), deterioration during accelerated ageing is associated with a decrease of total POD activity as well as that of other peroxide- and radical-scavenging enzymes.

Using polyacrylamide gel electrophoresis or isoelectric focusing to study the possibility that different isoperoxidases may be specifically expressed during seed ageing, distinct isoenzyme profiles have been documented in deteriorated seeds (Priestley, 
1986). Little data have been reported on relationships between changes in total peroxidase activity and corresponding quantitative and qualitative variations of enzyme isoforms with respect to their localization. In artificially aged peanut seeds, peroxidase activity has been measured separately in cotyledons and embryo axis, the latter being found to have most of the activity (Jeng and Sung, 1994; Sung and Jeng, 1994). Some POD activity has been detected in the husk and in the transparent or green layer of the pericarp of barley (Cochrane et al., 2000) and in the integument of Brassica juncea (Le Beller et al., 1986) and soybean (Schmitz et al., 1997). In imbibed Brassica oleracea seeds, enzyme activity measured in the integument and in the cotyledons was higher than in the embryo axis at the start of imbibition (Bellani et al., 2002). Contrasting results may be due also to applied experimental protocols. In most studies, differences in aged seeds have been averaged, combining germinating and non germinating seeds before any analysis is made. This procedure is acceptable for unaged, highly viable seed lots, in which few seeds fail to germinate, but not for studying the physiological state of deteriorated seed lots, in which the percentage of unviable seeds increases with ageing. In this case, the extraction procedure should be made on germinating seeds within a deteriorated seed lot, instead of a bulk extraction carried out on the entire seed lot.

In this paper we report peroxidase activity in radish (Raphanus sativus L.) seeds during accelerated ageing. We use polyacrylamide gel electrophoresis and cytochemical analysis to investigate total peroxidase activity, isoenzyme changes and cell localization in integument, cotyledons and embryo axis of deteriorated seeds.

\section{MATERIALS AND METHODS}

Radish (Raphanus sativus L. cv tondo rosso precocissimo $2^{\prime}$ ) seeds with $100 \%$ germination $(G)$ were used for the trials.

Accelerated ageing, germination test and sample preparation

Seeds were deteriorated by accelerated ageing technique (Delouche and Baskin, 1973) at $45^{\circ} \mathrm{C}$ and $100 \%$ relative humidity for 5 days. Sublots of aged seeds were collected every day, sealed in glass bottles and stored in a desiccator at $5^{\circ} \mathrm{C}$.
The germination test was carried out on five replicates of 20 seeds each in $9 \mathrm{~cm}$ Petri dishes containing two sheets of Whatman No. 1 filter paper imbibed with $10 \mathrm{ml}$ distilled water at $25^{\circ} \mathrm{C}$ in the dark. Seeds with a radicle length of 1-2 mm were considered to have germinated. Counts of germinating seeds were made at $48 \mathrm{~h}$ and when maximum germination was achieved.

At $48 \mathrm{~h}$ imbibition, germinated seeds with $2 \mathrm{~mm}$ length radicle from each aged sublot were sorted: integument, cotyledons and embryo axis were separated by scalpel and immediately used for biochemical and cytochemical assays. The cytochemical test was carried out also on $48 \mathrm{~h}$ ungerminated aged seeds. The aleurone and hyaline layer, strictly joined to the integument, were considered with this seed portion, although of different embryogenetic origin.

\section{Electrical conductivity assay}

Twenty seeds in five replicates were transferred to $25 \mathrm{ml}$ flasks containing $20 \mathrm{ml}$ water and incubated at $25^{\circ} \mathrm{C}$ for $24 \mathrm{~h}$ on a rotary shaker. At the end of incubation, the surface of seeds was dried, the seeds weighed, and the related leachate electrical conductivity (EC) was measured by a conductive meter (HI9032, Hanna Inst.) and reported as percentage change of unaged seed basis.

\section{Peroxidase spectrophotometric assay}

$500 \mathrm{mg}$ of each tissue were placed in $2 \mathrm{ml} 0.1 \mathrm{M}$ potassium phosphate buffer, $\mathrm{pH}$ 6.1, and homogenized in a cold mortar and pestle for $2 \mathrm{~min}$. After centrifugation for $15 \mathrm{~min}$ at $13000 \mathrm{~g}$, the resulting supernatant was cleaned by removing a floating lipid layer and used as enzyme source of soluble POD activity.

Supernatant protein content was determined using the Bio-Rad dye reagent with bovine serum albumin as standard (Bradford, 1976). The POD activity assay was carried out at room temperature according to the method of Markkola et al. (1990). An aliquot of $0.25 \mathrm{ml}$ supernatant was added with $3 \mathrm{ml}$ distilled water, $1 \mathrm{ml}$ of $0.1 \mathrm{M}$ phosphate buffer, $\mathrm{pH}$ 6.2, $0.5 \mathrm{ml}$ of $2 \mathrm{M} \mathrm{H}_{2} \mathrm{O}_{2}$ and $0.25 \mathrm{ml}$ of $10 \mathrm{mM} \mathrm{3,3}$, dimethoxybenzidine dihydrochloride (o-dianisine, Sigma). The reaction was run against a non-enzyme blank. The effect of sodium dodecyl sulphate (SDS) on enzyme activity was tested by incubating o-dianisidine and $\mathrm{H}_{2} \mathrm{O}_{2}$ with a standard enzyme (horserad- 
ish POD type VI, Sigma) in the presence of $2 \%$ (w/v) SDS. The absorbance was measured at $470 \mathrm{~nm}$ for 5 min using a spectrophotometer (Cary-1 Varian) and reported as increase in absorbance per fresh weight of sample during the first minute of incubation $\left(\mathrm{A}_{470 \mathrm{~nm}} \mathrm{~g}^{-1} \mathrm{~min}^{-1}\right)$.

\section{Separation of peroxidase isoenzymes by PAGE}

Native polyacrylamide gel electrophoresis (PAGE) was performed using a Biorad Protean apparatus according to the manufacturer's instructions. 4\% $(\mathrm{w} / \mathrm{v})$ and $9 \%(\mathrm{w} / \mathrm{v})$ acrylamide were used for stacking and separating gels, respectively. Aliquots of 30 $50 \mu \mathrm{l}$ containing $50 \mu \mathrm{g}$ of total proteins from integument, cotyledon and embryo axis samples were loaded on the gel. Electrophoresis was run at room temperature at $120 \mathrm{~V}$ for $60 \mathrm{~min}$. On completion, the gel was stained for POD activity for 30 min with a freshly prepared solution of $10 \mathrm{mM} 10 \%$ o-dianisidine in $0.1 \mathrm{M}$ acetate buffer $\mathrm{pH} 4.5$, replaced at the end of incubation with a $0.03 \%(\mathrm{v} / \mathrm{v}) \mathrm{H}_{2} \mathrm{O}_{2}$ in the same buffer until POD bands were visible. To estimate molecular mass (MM), PAGE was carried out as above, except that the gels and running buffer contained $2 \%(\mathrm{w} / \mathrm{v})$ SDS. The mild procedure allowed a separation of various isoforms on the basis of molecular mass and preserved POD activity, according to experimental protocol used to separate peroxidase isoenzyme pattern in the skin of maturing tomato fruit (Andrews et al., 2000). A set of prestained molecular mass marker proteins (with a broad range of 180 - $26.6 \mathrm{kDa}$, Sigma) was included with crude extracts. After running, the gels were stained for peroxidase activity as described above.

The POD profiles on the gels were captured with a high resolution commercial scanner (JX-330 Sharp model), and the scans were analysed with Imagemaster 1D v3 software package (Amersham Pharmacia Biotech). Quantitative analysis of isoenzyme bands were made by determining the optical density of the relative protein band peak, according to Collins et al. (1995). The results are the average of three replicates expressed as percentage of corresponding unaged seed bands.

\section{Localization and cytochemical assay}

Integument, cotyledons and embryo axis were frozen and sectioned with a cryostat. $10 \mu \mathrm{m}$-thick sections were incubated for POD localization in 20 $\mathrm{ml} 0.1 \mathrm{M}$ Tris- $\mathrm{HCl}$ buffer, $\mathrm{pH} 7.6$, containing 10 $\mathrm{mg}$ phenylendiamine, $20 \mathrm{mg}$ pyrocatechol and 0.2 $\mathrm{ml} 1 \%(\mathrm{v} / \mathrm{v})$ fresh $\mathrm{H}_{2} \mathrm{O}_{2}$. The control was performed without $\mathrm{H}_{2} \mathrm{O}_{2}$ (Gahan, 1984). Sections were observed and photographed soon after staining.

\section{RESULTS}

When radish seeds were aged under accelerated ageing conditions over 5 days, final cumulative germination dropped from 100 to $52 \% \mathrm{G}$ (Fig. 1A). Seed leachate electrical conductivity, expressed as

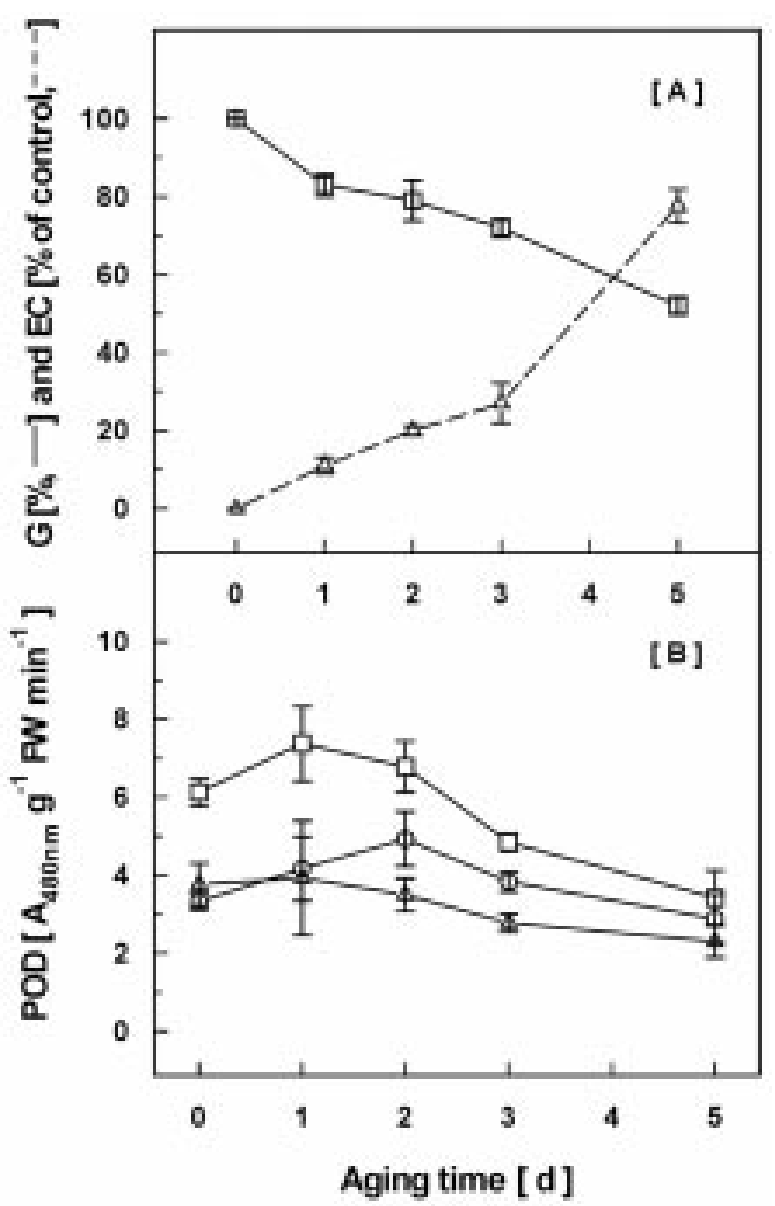

Fig. 1 - A, germination (G) and electrical conductivity (EC), and $\mathrm{B}$, peroxidase activity in radish seeds deteriorated under accelerated ageing conditions. Symbols are as follows: final cumulative germination $(\square)$, electrical conductivity $(\Delta)$ and peroxidase activity in integument $(\square)$, cotyledons $(O)$ and embryo axis $(\Delta)$. Values are means of five replicates of 20 seeds for the germination and electrical conductivity test, respectively, and of 100 seeds for the peroxidase activity assay. Vertical bars represent SE. 
percentage of unaged seed basis, increased with ageing, reflecting substantial membrane damage. Total POD activity in the crude extract of integument, cotyledons and embryo axis of $48 \mathrm{~h}$ germinated seeds during ageing is shown in Fig. 1B. The period of $48 \mathrm{~h}$ was chosen because preliminary experiments

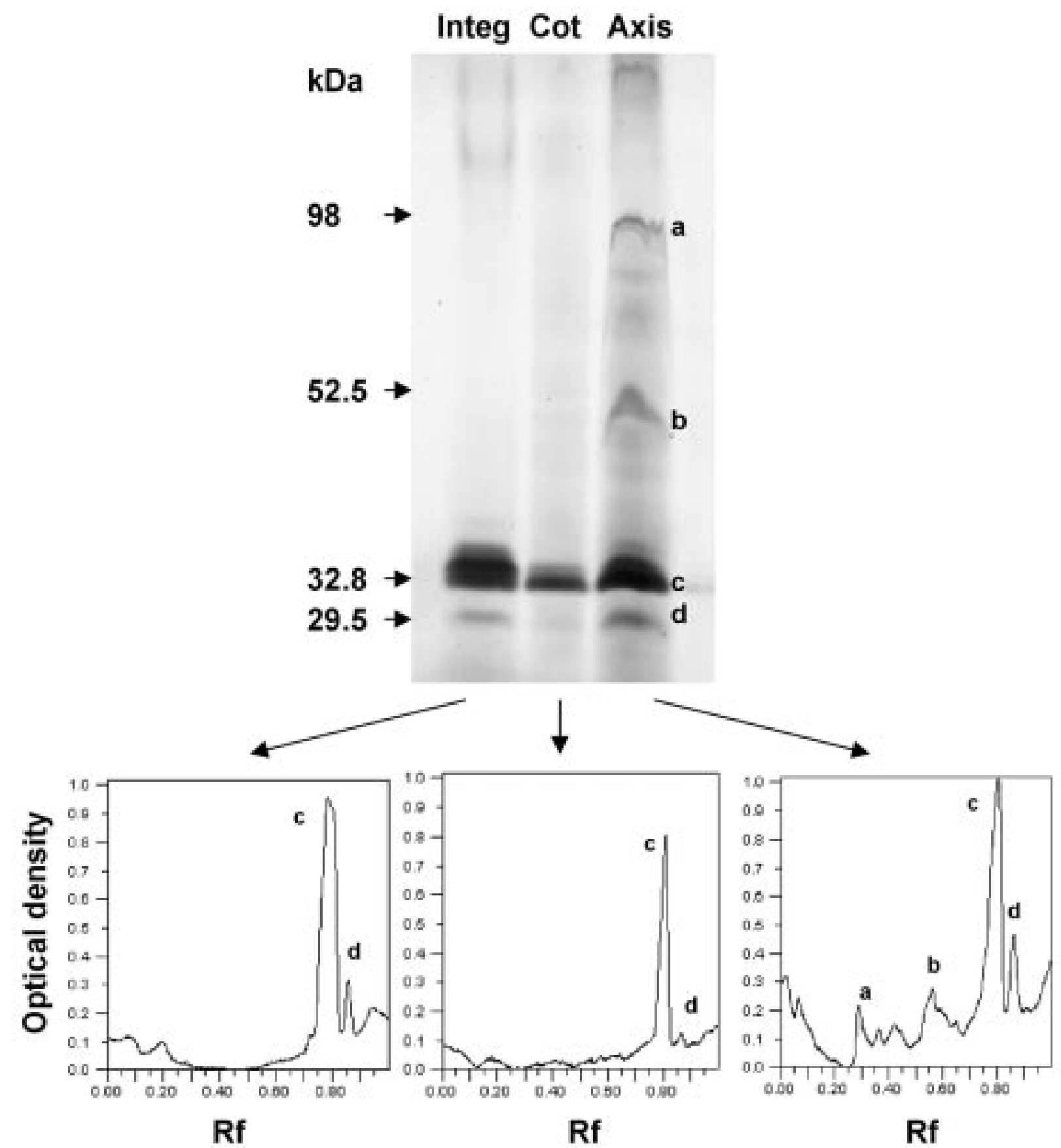

Fig. 2 - Native PAGE pattern and peak intensity profiles of peroxidase activity in the crude extracts obtained from integument, cotyledons and embryo axis of unaged radish seeds germinated at $48 \mathrm{~h}$ with a $2 \mathrm{~mm}$ length radicle. MM of isoenzymes (indicated by letters a - $\mathrm{d}$ on the right of the gel) on the left side of the gel were calculated by running standard MM proteins in a parallel SDS-PAGE separation. 
confirmed a progressive increase in enzyme activity in all three anatomical parts of unaged seed from 0 to $48 \mathrm{~h}$ imbibition (data not shown). Total enzyme activity in integument was greater than that in other seed parts and its increase up to two days of ageing, as shown also in cotyledons, was followed by a drastic decrease at $5 \mathrm{~d}$ ageing, when germination was
$52 \%$. In the embryo axis, POD activity decreased slowly, as ageing proceeded.

Several POD isoenzymes were present in the integument, cotyledons and the embryo axis, as shown by PAGE analysis (Fig. 2). Molecular mass assigned to the isoenzymes was calculated by SDSPAGE after partial denaturation in diluted SDS.

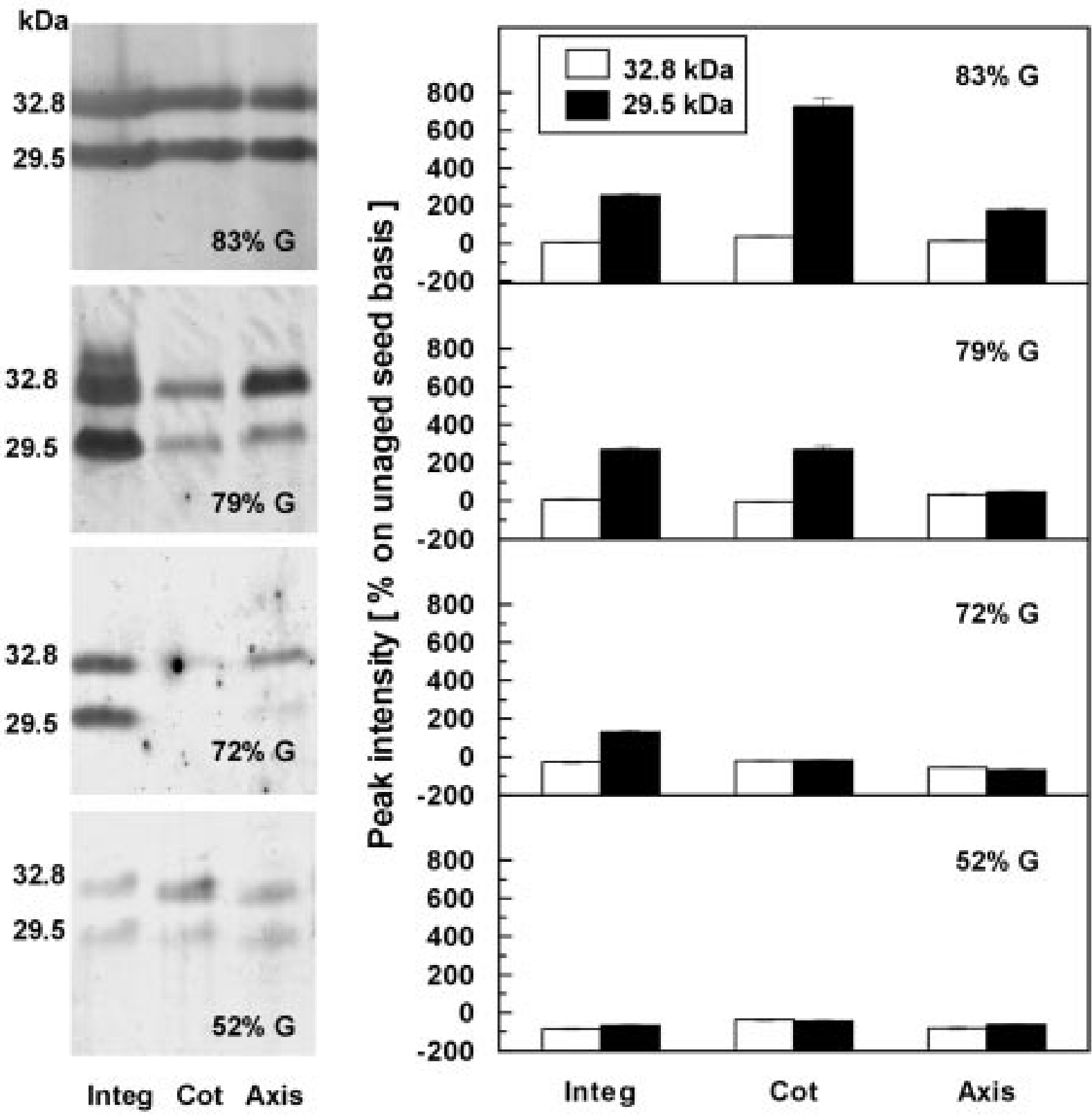

Fig. 3 - Partial gels with 32.8 and $29.5 \mathrm{kDa}$ peroxidase isoforms (on the left) and their corresponding percentage variation of peak intensity on unaged seed basis, (on the right), in integument, cotyledons and embryo axis of differently aged radish seeds germinated at $48 \mathrm{~h}$ with a $2 \mathrm{~mm}$ length radicle. Vertical bars represent SE. 
The densitometric analysis allowed to compare peaks of POD between control and aged seeds. In integument and cotyledons, a more abundant isoenzyme of $32.8 \mathrm{kDa} \mathrm{MM}$, and one of $29.5 \mathrm{kDa} \mathrm{MM}$ were separated. In the embryo axis, two other POD isoforms of 98 and $52.5 \mathrm{kDa} \mathrm{MM}$ were detected. Their peak intensity was lower than that of the 32.8 and $29.5 \mathrm{kDa}$ isoenzymes, and disappeared in the axis at the beginning of ageing (data not shown).

POD activity of isoenzymes with low MM was investigated in aged seeds (Fig. 3). A POD isoform with $32.8 \mathrm{kDa} \mathrm{MM}$ was constant in integument, cotyledons and axis of seeds with 83, 79 and $72 \%$ $\mathrm{G}$ final germination, and slightly declined in seeds with $52 \% \mathrm{G}$. The activity of $29.5 \mathrm{kDa} \mathrm{MM}$ isoenzyme increased (235\% of control) in integument of seeds with $83 \% \mathrm{G}$, was stable in seeds with $79 \%$ $\mathrm{G}$, and then declined in seeds with 72 and $52 \% \mathrm{G}$. The same trend was also evident in cotyledons, where the highest (638\% of control) POD activity was found in seeds with $83 \%$ G. In the axis, an appreciable increase (189\% of control) in isoenzyme activity was detected in seeds with $83 \% \mathrm{G}$, followed by a strong reduction in seeds with 72 and $52 \% \mathrm{G}$.

The localization of POD activity was studied at $48 \mathrm{~h}$ imbibition in tissues of seeds with different viability level and growing state (Fig. 4): germinated unaged seeds $(100 \% \mathrm{G})$ and ungerminated extremely aged seeds $(52 \% \mathrm{G})$. A comprehensive observation allows to describe the anatomy of the seeds. The seed coat is constituted by an external layer of epidermal mucilaginous cells, a palisade layer with thickened cell walls, and a pigmented layer formed by parenchymal cells. Some endosperm cells persist in the late seed development to form an aleurone layer closely associated with the integument, and a hyaline layer is joined to the aleurone. Two cotyledons with oil drops and protein bodies are folded along the mid axis to envelop the embryo. Generally, in aged germinated seeds, POD activity was localized in the same tissues of control (data not shown), whereas in ungerminated seeds, enzyme activity declined or disappeared in some tissues. In integument of unaged seeds, the localization of POD activity was observed in the cells of pigmented layer, in the wall and in the cytoplasm of the aleurone cells, and in the cells of the hyaline layer (Fig. 4A). In aged seeds, POD activity was found in the pigmented layer and in the aleurone cells, heav- ily stained or sometimes empty, but disappeared from the hyaline layer (Fig. 4B). In the cotyledon of highly viable seeds, POD activity was associated with the cells of the epiderm and with xylematic elements (Fig. 4C), while in those of aged seeds enzyme activity was mostly observed in not well differentiated xylem elements (Fig. 4D). In the embryo axis of unaged seeds, POD activity was associated with epidermal and procambial cells and with xylematic elements (Fig. 4E). In the extremely aged embryo axis, a slight peroxidase activity was localized in the cells of epidermis and external cortex layers and in the tunica at the level of the future leaf primordium (Fig. 4F).

\section{DISCUSSION}

Decrease in isoenzyme activity together with other physiological and biochemical changes have been reported as markers of seed ageing (McDonald, 1999). Our results on total peroxidase activity seem to confirm this trend in extremely deteriorated seeds $(52 \% \mathrm{G})$, whereas aged seed lots which maintained high viability showed an increase in POD activity in two distinct parts of the seed, integument and cotyledons. A more detailed analysis, using PAGE and a cytochemical localization of peroxidase activity in seed tissues, provided a partial explanation of this data, apparently conflicting with other reports in the literature. The accumulation of $29.5 \mathrm{kDa} \mathrm{MM}$ isoenzyme in the integument and cotyledons of aged seeds, may be associated with the potential role of this peroxidase isoform in protecting lipid peroxidation during accelerated ageing. Many isoperoxidases have been found in the cell walls and vacuoles of vascular plants and they seem to play a role in lignification of cell walls (Gaspar et al., 1985). Moreover, in cell culture of pepper, accumulation of POD has been reported to be a sign of a defense reaction by lignification prior to fungal invasion reactions (Egea et al., 2001). In deteriorated radish seeds, the persistent high level of $29.5 \mathrm{kDa} \mathrm{MM}$ isoenzyme in the integument of seeds with 83,79 and $72 \% \mathrm{G}$ seems to confirm the hypothesis of an indirect physiological response of seed to contrast the weakness of membrane integrity, as shown by seed leachate electrical conductivity data. It is noteworthy that this POD isoform, contrary to that with $32.8 \mathrm{kDa} \mathrm{MM}$, showed the highest activity increase in cotyledons 

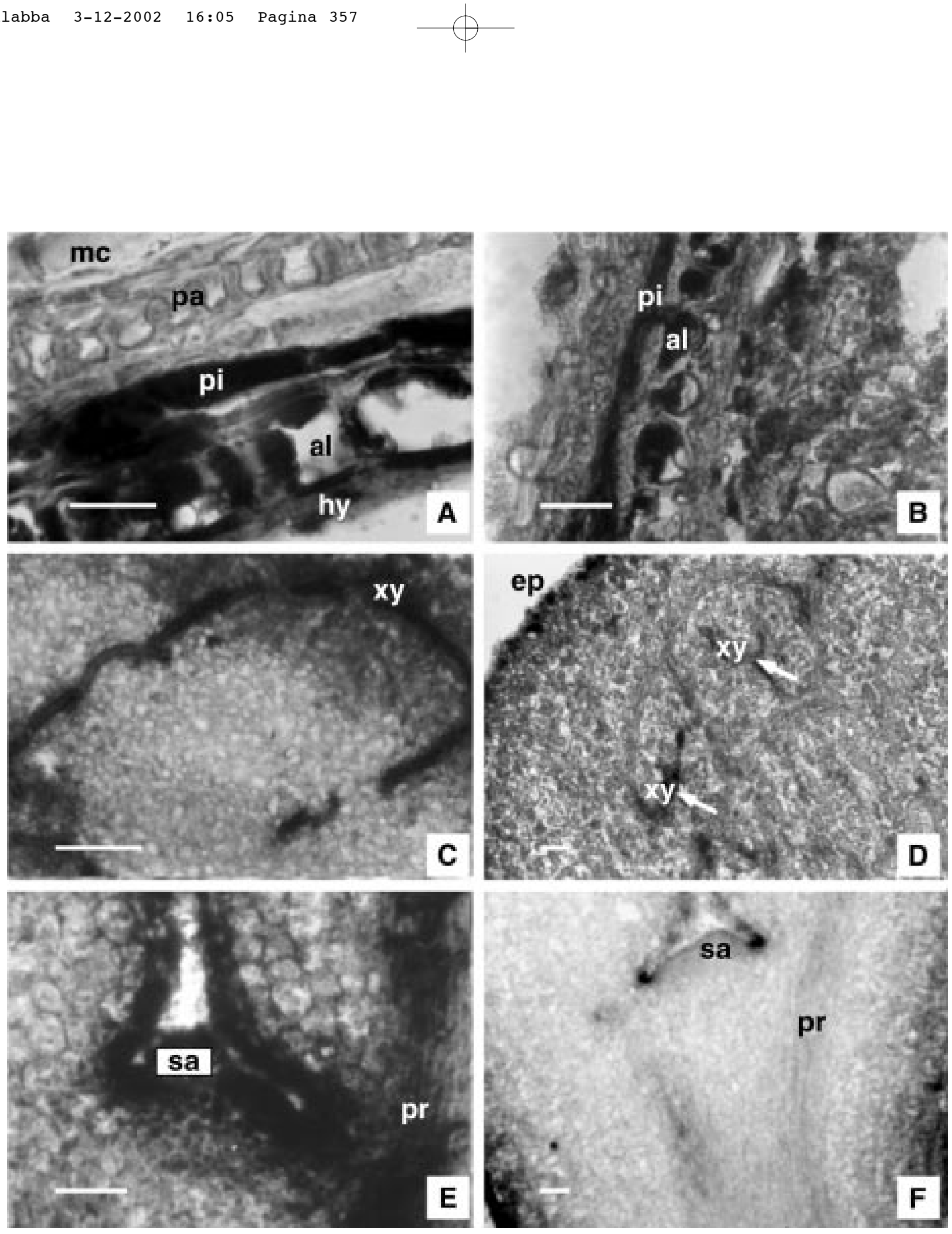

Fig. 4 - Histochemical localization of peroxidase activity in tissues of unaged and 48h germinated (A, C and E) and ungerminated, aged with $52 \% \mathrm{G}(\mathrm{B}, \mathrm{D}$ and F) radish seeds: integument (A and B), cotyledons (C and D) and shoot apex (E and F). Sections of unaged and aged seeds showing the following layers: mc, mucilaginous cells; pa, palisade; pi, pigmented; al, aleurone; hy, hyaline; xy, xylem elements; ep, epidermal cells; pr, procambial cells; sa, shoot apex. Arrows indicate sites of peroxidase activity. Bar $=10 \mu \mathrm{m}$.

of seeds with $83 \% \mathrm{G}$, which was progressively reduced with ageing. These findings also seem to indicate that the $29.5 \mathrm{kDa}$ MM isoenzyme, as detect- ed in cotyledons, could be a good marker of advancing seed deterioration. The 32.8 and $29.5 \mathrm{kDa} \mathrm{MM}$ isoenzymes are presumably coded by different 
genes or are accumulated differently in separate compartments of cells, which are more damaged in axis than the other two parts of the seed. In contrast to results of Sung and Jeng (1994) with aged peanut seeds, we did not find higher total peroxidase activity in the axis than in cotyledons, likely due to different ageing conditions.

More attention should be focused on relationships between isoenzyme patterns and deterioration of seeds. Even if many enzyme activities have been reported as biochemical markers of seed quality, results are difficult to compare because of experimental differences (Priestley, 1986). Our results also indicate that tissue localization of peroxidase activity along with PAGE characterization make relative isoenzyme patterns easier to be related to ageing.

\section{ACKNOWLEDGEMENTS}

This work was supported by a grant from Palermo University (ex 60\% grants) and Sicily Region (L.R. n. 25/93). The authors thank Dr C. Di Liberto for technical assistance with the electrophoresis experiments.

\section{REFERENCES}

Andrews, J., Malone, M., Thompson, D.S., Ho, L.C., and Burton, K.S.: Peroxidase isozyme patterns in the skin of maturing tomato fruit. Plant, Cell and Environm. 23, 415-422, 2000.

Bailly, C., Benamar, A., Corbineau, F., and Come, D.: Free radical scavenging as affected by accelerated ageing and subsequent priming in sunflower seeds. Physiol. Plant. 104, 646-652, 1998.

Bellani, L.M., Guarnieri, M., and Scialabba, A.: Differences in the activity and distribution of peroxidases from three different portions of germinating Brassica oleracea seed. Physiol. Plant. 114, 102 - 108, 2002.

Bradford, M.: A rapid and sensitive method for the quantification of microgram quantities of protein using the principle of protein-dye binding. Analyt. Biochem. 72, 248-254, 1976.

Chiu,K. Y., Wang, C. S., and Sung, J. M.: Lipid peroxidation and peroxide-scavenging enzymes associated with accelerated aging and hydration of watermelon seeds differing in ploidy. Physiol. Plant. 94, 441-446, 1995.

Cochrane, M.P., Paterson, L., and Gould, E.: Changes in chalazal cell walls and in the peroxidase enzymes of the crease region during grain development in barley. J. Exp. Bot. 51, 507520, 2000.

Collins, G.G., Nie, Xu-Li, and Saltveit, M.E.: Heat shock proteins and chilling sensitivity of mung bean hypocothyls. J. Exp. Bot. 46, 795-802, 1995.
Delouche, J.C., and Baskin, C.C.: Accelerated aging techniques for predicting the relative storability of seed lots. Seed Sci. Technol. 1, 427-452, 1973.

Egea, C., Ahmed, A.S., Candela, M., and Candela, M.E.: Elicitation of peroxidase activity and lignin biosynthesis in pepper suspension cells by Phytophtora capsici. J. Plant Physiol. 158, 151-158, 2001.

Gahan, P.B.: Plant Histochemistry and Cytochemistry. Pp. 215-216. Academic Press, London, 1984.

Gaspar, T., Penel, C., Castillo, F.J., and Greppin, H.: A twostep control of basic and acidic peroxidases and its significance for growth and development. Physiol. Plant. 64, 418423, 2001.

Gille, J.J.P., and Joenge, H.: Biological Significance of Oxygen Toxicity: An Introduction. In: Vigo-Pelfrey, C. (ed.): Membrane Lipid Oxidation. Pp. 1 - 32. CRC Press, Boca Raton, 1991.

Jeng, T.L., and Sung, J.M.: Hydration effect on lipid peroxidation and peroxide-scavenging enzymes activity of artificially age peanut seed. Seed Sci. Technol. 22, 531-539, 1994.

Le Beller, D., Picque, E., and Demignot, S: Peroxidase localization in the seeds of Brassica juncea. In: Greppin H., Penel C. Gaspar, Th. (ed.): Molecular and physiological aspects of plant peroxidases. pp 451-454. University of Geneva, Geneva, 1986.

Markkola, A.M., Ohtonen, R., and Tarvainen, O.: Peroxidase activity as an indicator of pollution stress in the fine roots of Pinus sylvestris . Water, Air, Soil Pollut. 52, 149-156, 1990.

McDonald, M.B.: Seed deterioration: physiology, repair and assessment. Seed Sci. Technol. 27, 177-237, 1999.

Priestley, D.A.: Morphological, structural, and biochemical changes associated with seed aging. - In: Priestley, D. A (ed.): Seed Aging - Implication of Seed Storage and Persistence in the Soil. Pp. 125-195. Comstock Publishing Associates, Ithaca, 1986.

Pukacka, S.: Changes in membrane lipid components and antioxidant levels during natural ageing of seeds of Acer platanoides. Physiol. Plant. 82, 306-310, 1991.

Schmitz, N., Gijzen, M., and van Huystee, R.: Characterization of anionic soybean ( Glycine max) seed coat peroxidase. Can. J. Bot. 75, 1336-1341, 1997.

Stewart, R.R.C., and Bewley, J.D.: Lipid peroxidation associated with accelerated aging in soybean axes. Plant Physiol. 65, 245-248, 1980.

Sung, J.M. Sung, and Chiu, C.C.: Lipid peroxidation and peroxide-scavenging enzymes of naturally aged soybean seed. Plant Sci. 110, 45-52, 1995.

Sung, J.M., and Jeng, T.L.: Lipid peroxidation and peroxidescavenging enzymes associated with accelerated aging of peanut seed. Physiol. Plant. 91, 51-55, 1994.

Wilson, D.O., and McDonald, M.B.: The lipid peroxidation model of seed deterioration. Seed Sci. Technol. 14, 269-300, 1986. 